TI 2015-020/IV

Tinbergen Institute Discussion Paper

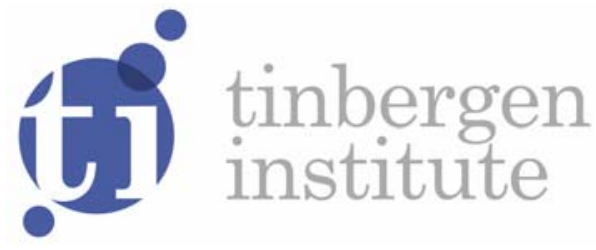

\title{
Banks and Market Liquidity
}

Stefan Arping

Faculty of Economics and Business, University of Amsterdam, and Tinbergen Institute, the Netherlands. 
Tinbergen Institute is the graduate school and research institute in economics of Erasmus University Rotterdam, the University of Amsterdam and VU University Amsterdam.

More TI discussion papers can be downloaded at http://www.tinbergen.nl

Tinbergen Institute has two locations:

Tinbergen Institute Amsterdam

Gustav Mahlerplein 117

1082 MS Amsterdam

The Netherlands

Tel.: +31(0)205251600

Tinbergen Institute Rotterdam

Burg. Oudlaan 50

3062 PA Rotterdam

The Netherlands

Tel.: +31(0)10 4088900

Fax: $+31(0) 104089031$

Duisenberg school of finance is a collaboration of the Dutch financial sector and universities, with the ambition to support innovative research and offer top quality academic education in core areas of finance.

DSF research papers can be downloaded at: http://www.dsf.nl/

Duisenberg school of finance

Gustav Mahlerplein 117

1082 MS Amsterdam

The Netherlands

Tel.: +31(0)20 5258579 


\title{
Banks and Market Liquidity*
}

\author{
Stefan Arping ${ }^{\dagger}$
}

December 19, 2014

\begin{abstract}
I study a model of market-liquidity provision by levered intermediaries that, besides operating trading desks, run deposit-taking franchises. Levered intermediaries' heightened incentive to absorb risk helps to counteract liquidity-provision frictions that, in an unlevered economy, would lead to price distortions and suppressed levels of asset origination ex ante. However, liquidity provision may also overshoot, leading to unhealthy price bubbles and causing asset origination to become excessive. Capital requirements are no panacea: They can spur risk taking and make bubbles bubblier. Ring fencing of trading activities can be, but is not necessarily, undesirable.
\end{abstract}

Keywords: Market Liquidity; Capital Requirements; Volcker Rule; Ring Fencing

${ }^{*}$ I thank Francesa Cornelli, Thierry Foucault, Frank de Jong, Patrick Tuijp, and Tanju Yorulmazer for very helpful comments and suggestions.

${ }^{\dagger}$ University of Amsterdam, Amsterdam Business School, Finance Group, Plantage Muidergracht 11, 1018 TV Amsterdam, The Netherlands, e-mail: s.r.arping@uva.nl, and Tinbergen Institute 


\section{Introduction}

The role of banks in creating liquidity by transforming illiquid assets into liquid liabilities (Diamond and Dybvig, 1983) and by extending credit lines (Holmström and Tirole, 1998; Kashyap, Rajan and Stein, 2002) is central to a large finance literature. The role of deposittaking intermediaries in providing investors with market liquidity - that is, in "making" financial markets - has received much less attention in the literature. What are the merits of combining deposit taking and market-liquidity provision under one roof? Does banks' engagement in market making entail costly externalities, and, if so, how should regulators respond? The objective of this article is to address these questions in a simple generalequilibrium model of market-liquidity provision by depository intermediaries.

As Duffie (2012a) notes, banks play a vital role in providing market liquidity. A leading example is the corporate bond market, in which banks traditionally facilitate much market making. Recently, though, banks' commitment to making markets has been in flux. Post-crisis policy initiatives concerning banks' engagement in trading and the way in which intermediary balance sheets ought to be funded or structured have led to the concern that regulation may over-constrain banks, causing them to reduce their market-making activities (for excellent discussions, see Duffie, 2012a,b; Thakor, 2012). Such policy initiatives include the Volcker Rule of the Dodd-Frank Act in the United States, which is intended to curb depository intermediaries' "proprietary" trading; heightened capital requirements (Basel III); and the European ring-fencing (or balance-sheet segregation) proposals. Even though these policy initiatives have yet to be (fully) implemented, the anticipation of such regulations - in conjunction with heightened scrutiny by regulators and society's aversion to risk taking in banking - may well reduce banks' risk appetite, causing them to become less eager to make markets. Indeed, this is precisely what seems to be happening at present in the corporate bond market, to the great concern of market observers. ${ }^{1}$

\footnotetext{
${ }^{1}$ For accounts in the press, see, for instance, Financial Times, "Markets: The debt penalty" (Sep. 10,
} 
The fundamental question yet to be answered is the following: If banks were to "exit" market-liquidity provision, would the corresponding drop in market liquidity be permanent? Or would we expect non-bank liquidity providers to fill the void left by banks? Answering this question requires first of all an understanding of whether and why bankaffiliated liquidity providers are special. One point of view might be that banks are special because of their privileged access to the taxpayer-subsidized safety net. Subsidies from underpriced government guarantees for bank debt, so it is often argued, cause banks to lever up excessively, distorting market outcomes and harming society. Regulators must, then, come to the rescue of society by curtailing banks' risk taking and requiring them to have more equity capital. My model will speak to this view; after all, government subsidization of banks, unappealing as it may be, seems to be an empirical fact (cf., Noss and Sowerbutts, 2012; International Monetary Fund, 2014). However, I will also argue that the traditional narrative is, in many ways, incomplete. Indeed, as I will explain in more detail below, it is precisely the removal of bail-out subsidies that would, in some cases, cause banks to become more more eager to absorb risk, to the potential benefit of society. I will also show that heightened capital requirements can have the unintended consequence of spurring risk taking, the welfare implications of which are a priori ambiguous.

My analysis rests on two premises. The first premise, which is central to a large literature on market microstructure and on the limits of arbitrage (for excellent surveys, see Gromb and Vayanos, 2010a; Vayanos and Wang, 2012; Foucault, Pagano and Roell, 2013), is that the process of market-liquidity provision is subject to frictions, raising the price of "immediacy" (Demsetz, 1968). Such frictions can stem from dealer risk aversion (Stoll, 1978, Grossman and Miller, 1988); adverse selection (Glosten and Milgrom, 1985; Kyle, 1985; Eisfeldt, 2004; Malherbe, 2014); intermediary market power (Duffie, Gârleneau and 2013); Euromoney, "The great bond market liquidity drought" (Oct. 2013); Financial Times, "Fears grow over steep decline in bond market liquidity" (Jul. 24, 2014); and Bloomberg, "Did bank rules kill liquidity? Volcker, Frank respond" (Oct. 20, 2014). See, also, BlackRock, "Got liquidity?" (Sep. 2012), and BNY Mellon, "The new liquidity: Investment implications of structural market changes" (Nov. 2012). 
Pedersen, 2005, 2007; Chacko, Jurek and Stafford, 2008); participation costs (Allen and Gale, 1994; Juang and Wang, 2010); or funding constraints (Shleifer and Vishny, 1997; Gromb and Vayanos, 2002, 2010b; Brunnermeier and Pedersen, 2009). A common theme of this literature is that frictions limit intermediaries' ability or willingness to absorb risk, causing prices to deviate from fundamentals. Thus, agents wishing to quickly liquify asset holdings in the wake of liquidity shocks may have to do so at "fire-sale" prices, leading to higher costs of capital and lower asset-origination levels ex ante. The second premise of my analysis is that safe and liquid bank liabilities (deposits, for short) command a "convenience yield," making them a relatively inexpensive funding device (cf., similar in spirit, Krishnamurthy and Vissing-Jorgensen, 2012; Stein, 2012; Moreira and Savov, 2013; DeAngelo and Stulz, 2014; Nagel, 2014). In my model, households demand safe stores of value, have limited outside options due to market segmentation, and are price takers, so deposit taking is an intrinsically profitable business activity for intermediaries. ${ }^{2}$ The key question is, then, whether intermediaries use the corresponding rents productively to support market-liquidity provision, or whether deposit-taking rents merely enrich shareholders.

The main point I wish to make follows from integrating the first premise with the second. By definition, deposit-taking intermediaries are levered, and, as is well known from the asset-substitution literature (e.g., Jensen and Meckling, 1976; Stiglitz and Weiss, 1981; Allen and Gale, 2000), levered agents can have a heightened incentive to take risk. A central tenet of the market-liquidity literature is that frictions can make liquidity providers averse to absorbing risk, thus distorting prices. The paper's main insight is now immediate: Levered intermediaries' heightened willingness to absorb risk can help to counteract frictions that, in an unlevered economy, would lead to fire-sale prices, causing asset origination

\footnotetext{
${ }^{2}$ In my model, bank liabilities are safe due to (implicit or explicit) public guarantees for the debt of "systemically important financial institutions," the need of which arises from the fact that banks, because of contracting imperfections, cannot commit to keep (highly risk-averse) households' claims safe. However, public guarantees for bank debt are not necessarily a source of government subsidization of banks in my model since the model's regulator can (and should) levy appropriate guarantee premia on banks.
} 
to be inefficiently low. Thus, society can benefit from levered intermediaries' heightened incentive to take risk: Prices move closer to fundamentals, improving asset-origination incentives ex ante. Safety-net subsidies are not required for this mechanism to play out: The mere threat of over-valued liabilities under their outside option of not absorbing risk can make intermediaries eager to absorb risk, causing them to rationally cross-subsidize market-liquidity provision with their proprietary profits from deposit taking.

However, levered intermediaries' heightened incentive to absorb risk can also have a cost. The flip side of the risk-taking effect is that liquidity provision may "overshoot," leading to unhealthy price bubbles (cf., also, Allen and Gale, 2000) and causing asset origination to become excessive. In this circumstance, asset originators squander valuable resources on the manufacturing of "toxic" assets that banks demand for their risk shifting (cf., Acharya, Cooley, Richardson and Walter, 2010). To quote Paul Volcker, in some cases, "there is such a thing as too much liquidity" (Bloomberg, October 24, 2014). In such cases, a reduction in market-liquidity provision is not necessarily detrimental to welfare.

I use this model to run a number of policy experiments. I first show that if society's objective is to encourage intermediaries to provide more liquidity, then regulators may not want to subsidize them through underpriced debt guarantees but do precisely the opposite and tax them (levy a "premium"). The effect of the tax is that it raises intermediaries' total liability burden; this, in turn, makes them eager to absorb more risk in an attempt to protect their deposit-taking profits against "taxation." Thus, relative to underpricing (subsidization), actuarially fair pricing - or even overpricing - of guarantees may induce intermediaries to absorb more risk, a result that is diametrically opposed to the perceived wisdom in the banking literature. A perhaps more important policy experiment is to introduce equity capital requirements. As discussed, one possible outcome in my model is that intermediaries take excessive risks and provide "too much" liquidity. The traditional response would be to require intermediaries to have more equity capital. I show that 
capital requirements are no panacea and, in fact, can backfire. In particular, capital requirements can spur intermediary risk-taking, create bubbles, and make existing bubbles bubblier. The intuition behind this result is simple: To limit windfall gains for liability holders, intermediaries seek to invest equity-issuance proceeds in risky assets. More money is chasing assets, leading to higher prices. However, while higher capital requirements can lead to higher asset prices in an equilibrium in which intermediaries do engage in negativeNPV trading, they also reduce the "likelihood" of such an equilibrium occurring. The overall effect of capital requirements on market outcomes is, then, ambiguous. ${ }^{3}$

Yet another reason why heightened capital requirements can exacerbate bubbles in my model is that they require intermediaries to raise more equity capital from investors, thereby reducing the capital available to investors for the purpose of collateralizing personal short-sale positions that would help mitigate bubbles. Bubble equilibria can also be robust to the possibility of short sales by intermediaries. In my model, profit opportunities from mispricing (prices exceeding discounted cash flows) do not arise from exogenous shocks to prices, but emerge endogenously from levered intermediaries' heightened incentive to absorb risk. Crucially, intermediaries may not necessarily want to take advantage of such "arbitrage" opportunities. This is because taking negative-NPV long positions may offer higher asset-substitution gains than taking positive-NPV short positions.

Finally, I show that balance-sheet segregation - ring fencing of trading activities - is not necessarily desirable, even if taxpayer money is not at risk. The essence of the ring-fencing policy proposals (Vickers et al., 2001; Liikanen et al., 2012) is that banks' core deposits must not be put at risk by their investment banking activities, such as trading. Ultimately, this means that deposits must be put into bankruptcy-remote subsidiaries whose prospects are not affected by the prospects of banks' trading businesses. In my model, the effect of

\footnotetext{
${ }^{3}$ The notion that heightened capital requirements do not necessarily make banks safer is also central to some of the literature on bank capital regulation (for an excellent review, see Thakor, 2014); see, among others, Koehn and Santomero (1980); Calem and Rob (1999); Blum (1999); and Hellmann, Murdock and Stiglitz (2000). However, the mechanisms highlighted in these articles are orthogonal to mine.
} 
ring fencing is that it enables banks to commit to not cross-subsidize liquidity provision with their profits from deposit taking. This is undesirable when liquidity-provision frictions cause prices to be below fundamentals. It is desirable when bubbles are severe.

Relation to the Literature. As outlined above, the thrust of my argument is that levered intermediaries' heightened incentive to absorb risk counteracts frictions that, in an unlevered economy, would lead to fire-sale prices and inefficiently low asset-origination levels. The observation that banks (also) play a key role in providing savers with debt-like stores of value closes the model. Thus, this article lies at the intersection of three strands of the literature (see the references provided earlier): (i) the literature on financial market liquidity; (ii) the asset-substitution literature, and (iii) the literature on banks' role in providing agents with stores of value. The effect of funding/capital constraints on intermediaries' risk-absorption capacity has been analyzed by a large literature (e.g., Gromb and Vayanos, 2002, 2010b; Brunnermeier and Pedersen, 2009; He and Krishnamurthy 2013). The focus of my analysis is, instead, on intermediary capital structure - i.e., the question of how the mix between "debt-tied" and "equity-tied" funding liquidity shapes market outcomes and ex ante asset-origination levels. A focal question of my paper is, then, whether banks use deposit-taking rents "productively" to support liquidity provision. This perspective complements Kashyap, Rajan and Stein (2002). In their model, deposit taking and funding-liquidity provision (through the extension of credit lines) are complementary due to imperfectly correlated liquidity shocks, a mechanism that is orthogonal to mine.

The paper also relates to the literature on rational bubbles. Allen and Gale (2000) present a model in which investors finance risky-asset purchases with debt, and in which the ensuing risk-shifting incentive causes investors to bid up asset prices, leading to bubbles. The costs of investors' excessive risk taking are supposed to be borne by other parties. In contrast, in my model, the costs of intermediaries' heightened risk taking may, ultimately, 
be borne by the intermediaries themselves. ${ }^{4}$ Acharya and Navqui (2012) develop a model in which, in contrast to mine, bubbles are caused by internal agency conflicts in banks. In their setting, heightened macroeconomic risk causes agents to hold more bank deposits; this "flight to quality" leaves banks flush with liquidity, lowering the sensitivity of loan officers' payoffs to downside risks and inducing excessive credit volume. Farhi and Tirole (2012) analyze the possibility of rational bubbles in a dynamic economy in which financially constrained firms demand and supply liquidity. A bubble is said to occur when the prices of non-dividend-paying assets exceed the present value of dividends (i.e., zero). In their model, bubbles are caused by agents' demand for stores of value that serve to alleviate future financial constraints arising from agency conflicts; thus, the more limited the pledgeability of corporate income, the more likely bubbles are to emerge. In contrast, in my (static) model, in which asset-price bubbles are caused by levered intermediaries' heightened risktaking incentive, a rise in return pledgeability widens the incidence of bubbles. ${ }^{5}$

The proposed model is stylized, and it abstracts from several real-world features that are relevant to banks' engagement in trading. For instance, the model does not make explicit the fact that the markets in which banks provide liquidity tend to be over-the-counter markets (Duffie, Gârleneau and Pedersen, 2005, 2007), and it abstracts from the fact that banks may also engage in lending and securities underwriting - activities that could be, but are not necessarily, synergistic with banks' engagement in trading (Arping, 2013). A question left to future research is why bank liquidity-providers are more active in some markets and less active in others. Relatedly, if banks have a cost-of-funding advantage due to their deposit-taking franchises, then what is the advantage of non-bank liquidityproviders ("prop shops")? When is one advantage more important than the other?

\footnotetext{
${ }^{4}$ See Barlevy (2014) for a model in which lenders extend loans to entrepreneurs (with positive-NPV projects) and speculators and cannot distinguish between these types of borrowers. The costs of levered speculators' excessive risk taking are, then, borne by entrepreneurs through a rise in borrowing costs.

${ }^{5}$ In a sense, my model highlights that a "bubble" in the "store-of-value" (here, deposit) market - agents "overpaying" for savings vehicles - can spill over to and create a bubble in the asset market.
} 


\section{The Model}

\subsection{Agents and Technology}

The model features three classes of agents: "asset originators," "liquidity providers" and "households." There is a single consumption good ("dollars"), which is also the numéraire. Liquidity providers and households are endowed with dollars, and asset originators are not. Let there be a continuum of size one of each class of agents.

There are three dates, $t=0,1,2$. At date 0 , asset originators can devote their human capital to creating long-term assets that pay off at date 2. For instance, the asset originators could be entrepreneurs originating projects, commercial banks originating credit lines, or mortgage brokers originating mortgage commitments. Originating $I$ units of long-term asset has a non-monetary cost of $\psi(I)=I^{2} / 2$. The basic problem is that the asset originators wish to consume at date 1 ("early"). Other agents do not wish to consume early, so there are gains from trade. Thus, at date 1, a (Walrasian) market opens in which agents can trade. ${ }^{6}$ Tradable assets are restricted to the long-term assets originated at date 0 and dollars. Short sales are momentarily excluded; however, I relax this assumption later.

The liquidity providers are owned and run by owner-managers, each with $K$ dollars of own funds. They are also endowed with a riskless storage technology that carries dollars from one period to the next. For the moment, I assume that investable funds are limited to $K$, but below, I will specialize the model to one in which the liquidity providers are banks that also run deposit-taking franchises, enabling them to raise additional funds from households. Households do not directly participate in asset markets. Asset originators maximize expected consumption at date 1, less the disutility from asset origination. Thus,

\footnotetext{
${ }^{6}$ The literal interpretation of this model might be one in which liquidity providers acquire assets in a primary market. However, it is straightforward to see that the model could be extended to one in which investors sell securities to liquidity providers in a secondary market (e.g., because of client redemption requests) - securities that they previously acquired from asset originators. Price levels in the secondary market, then, shape investors' willingness-to-pay in the primary market; this, in turn, shapes asset-origination incentives. My modeling approach should be viewed as a convenient shortcut.
} 
denoting the per-unit asset price by $p$, asset originators' problem is to maximize $I p-I^{2} / 2$, which yields $I=p$. Liquidity providers maximize terminal expected wealth.

Long-term asset payoffs are stochastic and depend on the state of the economy at date 2. In the good state of the economy, which occurs with probability $\theta \in(0,1)$, each unit of long-term asset generates a total payoff of $v_{h}>0$ for society, and in the bad state, it pays off $v_{l}=0$. I posit that asset payoffs are not fully pledgeable to investors: A fraction $\phi \in(0,1)$ can be pledged to investors, and the remainder is non-pledgeable. Nonpledgeability of returns could stem from adverse selection or agency problems. There is a large literature emphasizing this point (for excellent overviews, see Tirole, 2006, 2011); thus, for simplicity's sake, I do not explicitly model such frictions here (which would require complicating the model). As discussed in the Introduction, the role of frictions in market-liquidity provision is also central to a large literature on market microstructure and on the limits of arbitrage. Yet another possibility is that asset origination exerts a positive externality on society (consumer surplus, social benefits of home ownership, etc.), which investors fail to internalize. In any case, as in many other models, there is a wedge between private and social returns, so equilibrium asset prices and origination levels may be inefficiently low. In what follows, I refer to $V \equiv \theta v_{h}+(1-\theta) v_{l}$ as "fundamentals" and to $\phi V$ as "pledgeable income." In a frictionless, completely distortion-free economy-in which, by definition, all externalities are internalized - asset prices equal fundamentals. In this model, as in the real world, prices may be below, at or above fundamentals.

\section{$2.2 \quad$ No Intermediation}

As a useful benchmark, consider the case in which investable funds are limited to liquidity providers' own funds $K$. Taking the asset price $p$ as given, liquidity providers submit buy orders $B$ as to

$$
\max _{B \geq 0} B\left(\phi\left(\theta v_{h}+(1-\theta) v_{l}\right)-p\right)=B(\phi V-p)
$$


subject to the resource constraint $B p \leq K$. Thus, for $p<\phi V$, aggregate asset demand is $B=K / p$; for $p=\phi V$, it is $B \in[0, K / p]$; and for $p>\phi V$, it is $B=0$. Equating aggregate asset demand with aggregate asset supply, $B=I=p$, gives the equilibrium:

$$
B=I=p=\min [\phi V, \sqrt{K}]<I^{F B}=V,
$$

where $I^{F B}$ is the (unconstrained) efficient level of asset origination. The wedge between

fundamentals and equilibrium prices, $V-p=\max [(1-\phi) V, V-\sqrt{K}]>0$, can be thought of as a "fire-sale" discount. When investable funds $K$ are low, there is too little cash in the market to absorb the supply of assets at "fair" prices, pushing prices below pledgeable income $\phi V$. When investable funds are high, cash-in-the-market constraints are slack. Prices are below fundamentals $V$ due to limited pledgeability of returns.

\section{$2.3 \quad$ Intermediation}

While households do not directly participate in financial markets, they can invest in liquidity providers. Per liquidity provider, there is a unit mass of households, each with an endowment of $D>0$ that it must store for consumption at date 2. Households value consumption only at date 2 and are infinitely risk-averse. Their utility function is

$$
U\left(c_{0}, c_{1}, c_{2}^{h}, c_{2}^{l}\right)= \begin{cases}c_{2}=c_{2}^{h}=c_{2}^{l} & \text { if } c_{2}^{h}=c_{2}^{l}, \\ -\infty & \text { if } c_{2}^{h} \neq c_{2}^{l},\end{cases}
$$

where $c_{2}^{h}$ and $c_{2}^{l}$ denote date-2 consumption in the high and low states of the economy, respectively. Thus, the securities issued to households must be safe and take the form of debt claims. For the sake of brevity, I refer to these debt claims as deposits.

I posit that liquidity providers, due to deposit-contracting imperfections, cannot contractually commit to keep households' claims safe. Thus, unless society comes up with 
another mechanism of meeting households' demand for safe claims, households would be unwilling to give their dollars to liquidity providers, and intermediation would fail. Thus, let there be a benevolent (government) regulator that provides a guarantee for the deposit liabilities issued by liquidity providers. An important practical question is whether and how these guarantees are priced. Below, I will start with the case in which the guarantees are not priced, and deposit insurance is funded through general taxation (levied on agents outside the model). This may not be the most realistic case; nor is it particularly appealing - it merely serves as a benchmark for the analysis of the more interesting case in which guarantees are priced and do not involve subsidies. In a later section, I will also allow the regulator to impose equity capital requirements on intermediaries.

The intermediaries operate in local deposit markets, and they can accept deposits only from local households. Households can self-store dollars; however, they are less good at storage than the intermediaries are: Each dollar put into self-storage at date 0 yields $1-C$ dollars at date 2 , where $C \in(0,1)$. Households are price takers; thus, in equilibrium, each intermediary offers an effective gross deposit rate of $1-C$ (or, equivalently, a gross deposit rate of one and a per-dollar account fee of $C$ ). Thus, normalizing intermediary management costs to zero, $C$ is an intermediary's deposit-taking profit margin. It is simply the return that households are willing to give up for the banking services they receive.

In summary, the model plays out as follows. At date 0, asset originators exert effort to create long-term assets, and each liquidity provider (intermediary) collects deposits $d \leq D$ from households. Having collected deposits, intermediaries may also raise funds $k \leq K$ from their owners. At date 1, the asset market opens; agents trade long-term assets for dollars; and asset originators consume. At date 2, the long-term assets pay off; payments are made; and households and intermediary owner-managers consume. 


\section{Equilibrium}

\subsection{Non-Priced Guarantees}

I start with the case in which public guarantees for intermediary debt are not priced.

Taking the asset price $p$ as given, an intermediary collects deposits $d \leq D$, raises equity capital $k \leq K$ from its owners, and submits a buy order $B \leq(d+k) / p$. The intermediary may, then, be left with excess cash $S=d+k-B p \geq 0$, which is invested in the storage technology. Intermediaries' problem is to maximize shareholder value-added,

$$
\max _{(d \leq D, k \leq K, B \geq 0)} W=\theta\left(B \phi v_{h}+S-d(1-C)\right)+(1-\theta) \max \left[0, B \phi v_{l}+S-d(1-C)\right]-k,
$$

subject to the resource constraint $B \leq(d+k) / p$. By $v_{l}=0$ and $v_{h}=V / \theta$, shareholder value-added $W$ can be rewritten as

$$
W=B(\phi V-p)+d C+\underbrace{(1-\theta) \max [d(1-C)-\overbrace{(d+k-B p)}^{=S}, 0]}_{\text {reduction MV liabilities }} .
$$

The first term is the "trading" profit; the second term is the profit from deposit taking; and the third term is the difference between the market value of liabilities when the intermediary does not engage in trading $(B=0)$ and the market value of liabilities when it does $(B>0)$. In other words, the third term represents the amount by which engaging in risky trading allows the intermediary to reduce the market value of its liabilities. This is nothing else than the standard asset-substitution (or risk-shifting) gain from risk taking.

I now solve for the equilibrium. Clearly, intermediaries will always exhaust their deposit-taking opportunities, $d=D$. Furthermore, when prices are below pledgeable income, $p<\phi V$, it is optimal to maximize asset purchases by raising as many dollars as possible and using them to buy assets, $B=(D+K) / p$. The interesting case occurs when 
prices are above pledgeable income, $p>\phi V$. Obviously, intermediaries will not waste their owners' funds on negative-NPV asset purchases, so $k=0$. The problem reduces to

$$
\max _{B \geq 0} W=B(\phi V-p)+D C+(1-\theta) \max [B p-D C, 0]
$$

subject to the resource constraint $B \leq D / p$. Assuming that $p \leq \phi V / \theta$ holds in equilibrium and verifying later, this problem has a corner solution at either $B=0$ or $B=D / p$. Intermediaries weakly prefer $B=D / p$ to $B=0$ if and only if

$$
\underbrace{(1-\theta) D(1-C)}_{\text {asset-substitution gain }} \geq \underbrace{D / p \times(p-\phi V)}_{\text {trading losses }} .
$$

The key observation is that negative-NPV trading can occur in equilibrium. The reason is that intermediaries' asset valuation can exceed pledgeable income due to their private benefits (asset-substitution gains) from investing in risky assets. Eq. (1) reduces to

$$
p \leq \frac{\phi V}{1-(1-\theta)(1-C)} \equiv \hat{p} \in(\phi V, \phi V / \theta)
$$

The following result is now immediate:

Lemma 1 Optimal asset demand is

$$
B \in \begin{cases}\{(D+K) / p\} & \text { for } p<\phi V, \\ {[D / p,(D+K) / p]} & \text { for } p=\phi V, \\ \{D / p\} & \text { for } p \in(\phi V, \hat{p}), \\ \{0\} \cup\{D / p\} & \text { for } p=\hat{p}, \\ \{0\} & \text { for } p>\hat{p} .\end{cases}
$$

In the first case, trading has positive NPV, so intermediaries raise as many dollars as possible and use them for asset purchases. In the second case, trading has zero NPV, so 
intermediaries are indifferent between any $B \in[D / p,(D+K) / p]$. In the remaining cases, trading has negative NPV, so $k=0$. In the third case, intermediaries strictly prefer trading to no trading due to the asset-substitution gains from trading. In the fourth case, they are indifferent between $B=0$ and $B=D / p$. In this case, there is a mixed trading equilibrium in which some intermediaries trade and others do not.

Proposition 1 (non-priced guarantees) The equilibrium is as follows:

(i) For $D<(\phi V)^{2}-K: d=D, k=K$, and $p=B=I=\sqrt{D+K}<\phi V$.

(ii) For $D \in\left[(\phi V)^{2}-K,(\phi V)^{2}\right]: d=D, k=(\phi V)^{2}-D$, and $p=B=I=\phi V$.

(iii) For $D \in\left((\phi V)^{2}, \hat{p}^{2}\right]$, where $\hat{p}=\phi V /(1-(1-\theta)(1-C)): d=D, k=0$, and $p=B=I=\sqrt{D}>\phi V$.

(iv) For $D>\hat{p}^{2}: d=D, k=0, p=I=\hat{p}>\phi V$, and a mixed trading equilibrium in which a fraction $\hat{p}^{2} / D<1$ of intermediaries buy $B=D / \hat{p}>\hat{p}$ asset units, and the others do not trade $(B=0)$.

Proof. Parts (i) to (iii) follow from Lemma 1 and market clearing, $(D+k) / p=p$. To prove part (iv), note that, at $p=\hat{p}$, intermediaries are indifferent between $B=0$ and $B=D / \hat{p}$ (Lemma 1). Letting $\alpha$ denote the fraction of intermediaries that trade, market clearing amounts to $\alpha D / \hat{p}=\hat{p}$, which reduces to $\alpha=\hat{p}^{2} / D<1$.

Figure 1 illustrates the proposition. A first observation is that equilibrium prices can exceed pledgeable income $\phi V$. This occurs when the supply of "debt-tied" funding liquidity $D$ is sufficiently high, $D>(\phi V)^{2}$. In contrast, a rise in "equity-tied" funding liquidity $K$, despite leading to higher average prices, does not affect the range of parameter values under which prices exceed pledgeable income. This is because intermediaries would not waste their owners' funds on negative-NPV trades (unless they are required to raise equity; 


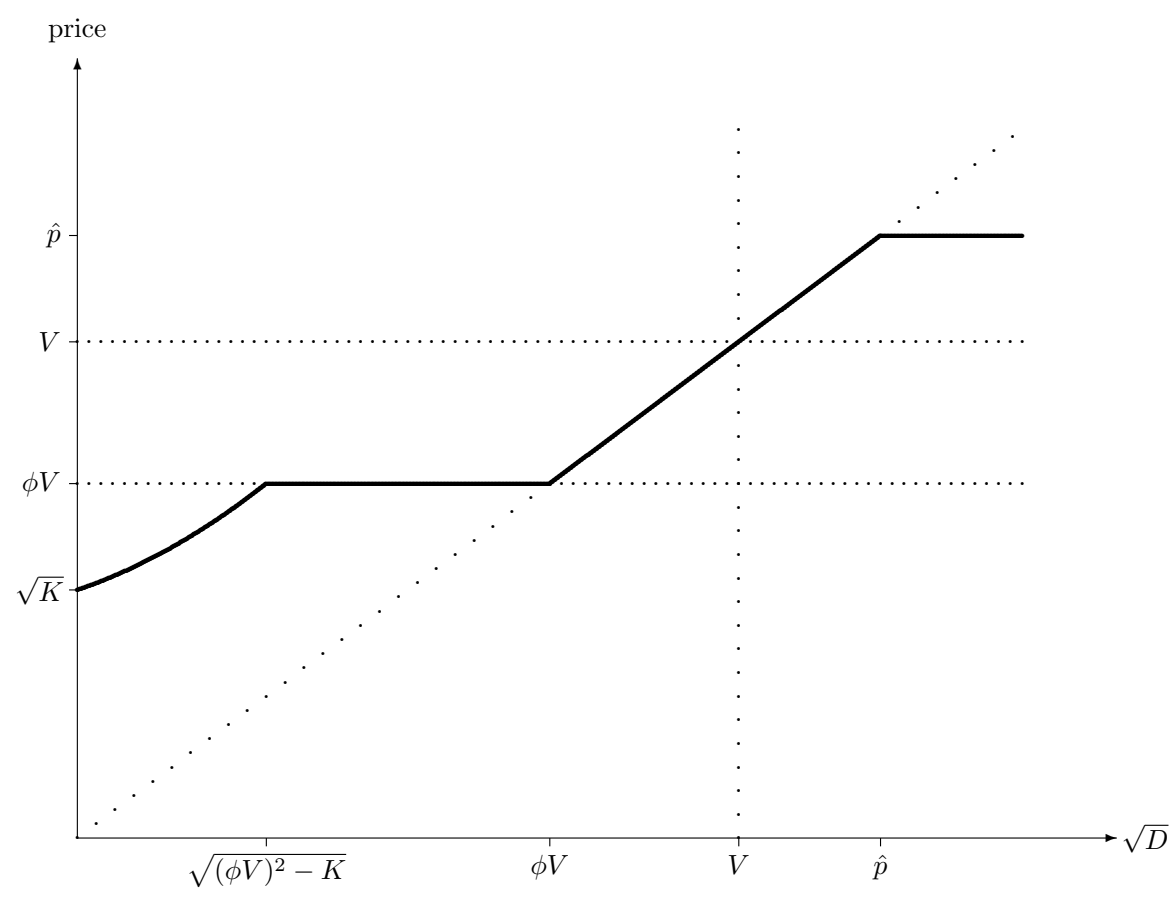

The solid line depicts the equilibrium price $p$ as a function of (the square root of) debt-tied funding liquidity $\sqrt{D}$. For $\sqrt{D}>\phi V$, prices exceed pledgeable income $\phi V$. For $\sqrt{D}>V$, prices exceed fundamentals $V$, causing asset origination to become excessive.

Figure 1: Equilibrium (case $\left.1-\phi<(1-\theta)(1-C), K<(\phi V)^{2}\right)$

see below), and intermediaries' owners, if they could invest on their own, also would not engage in negative-NPV trades. ${ }^{7}$ However, a rise in equity-tied funding liquidity reduces the range of parameter values under which prices are below pledgeable income.

The key question for welfare is whether prices are below or above fundamentals $V$. As Figure 1 illustrates, there is a range of parameter values under which prices are above pledgeable income but below fundamentals. In this case, society benefits from overpricing (relative to pledgeable income) through its effect on ex ante asset-origination incentives. Levered intermediaries' heightened incentive to absorb risk mitigates price distortions that cause asset prices to be inefficiently low. However, there can also be a range of parameter

\footnotetext{
${ }^{7}$ If short sales were allowed for, a rise in equity-tied funding liquidity would reduce the range of parameter values under which prices exceed pledgeable income. This is because, as $K$ rises, intermediaries' owners have more capital available for the purpose of collateralizing personal short-sale positions. See Section 5 .
} 
values under which equilibrium prices exceed fundamentals $V$ and, thus, are inefficiently high. Specifically, a "bubble" $\left(p>V\right.$ ) occurs if and only if (i) $D>V^{2}$, and (ii) $\hat{p}>V$-i.e., the wedge between social and private returns is not too high,

$$
1-\phi<(1-\theta)(1-C)
$$

Thus, if condition (2) holds, then, as debt-tied funding liquidity $D$ rises, market-liquidity provision eventually overshoots, leading to an unhealthy price bubble and causing ex ante asset-origination levels to become excessively high (see Figure 1).

Another interesting observation is that, with non-priced guarantees, intermediaries' overall profits are never below their deposit-taking rents. The immediate implication is that liquidity-provision losses are not borne by the intermediaries, but by the regulator and, thus, the taxpayer or society at large. To see this more formally, note that the overall profit of an intermediary that is active in trading can be expressed as

$$
W=B(\phi V-p)+D C+\underbrace{(1-\theta) D(1-C)}_{\text {loss regulator }} .
$$

The first term is the profit from liquidity provision (trading); the second term is the profit from deposit taking (before subsidies); and the third term is the regulator's loss from guaranteeing intermediary debt. The regulator's loss is intermediaries' gain, so it represents a taxpayer-funded subsidy to intermediaries. Trading losses are highest at $p=\hat{p}$, at which $B(\phi V-p)=-(1-\theta) D(1-C)$. Thus, safety-net subsidies (more than) compensate for the trading losses that intermediaries may incur. Deposit-taking profits are not used productively to support market-liquidity provision, but flow straight into shareholders' pockets. The question arises whether society can do better, and, next, I show how. 


\subsection{Liquidity Provision in a Subsidy-Free Economy}

So far, I have considered an economy in which intermediary debt is subsidized by the state through underpriced guarantees. This section analyzes liquidity provision in a subsidyfree economy. The environment I have in mind is one in which society is highly averse to subsidizing banks with taxpayers' money, so that the regulator faces a mandate to price guarantees in a way that he (at least) breaks even on the guarantees. The key question is whether loss-making liquidity provision can be an equilibrium outcome once safety-net subsidies are removed. I will show that the answer to this question is affirmative and, interestingly, that intermediaries' eagerness to absorb risk may be strengthened.

Consider a candidate equilibrium in which intermediaries raise deposits $D$ and, possibly, additional funds from their owners, and invest these funds in risky assets. Thus, intermediary $i$ fails with probability $1-\theta$, in which case the regulator compensates depositors at cost $D(1-C)$, and it does not fail with probability $\theta$. Let the regulator levy a per-dollar-of-deposits premium $T>0$ (or "tax") on intermediaries, due at date 2. Given this premium, the regulator's equilibrium profit from guaranteeing intermediary debt is $\theta D T-(1-\theta) D(1-C)$. Thus, the actuarially fair premium at which the regulator's expected profit is just zero is

$$
T^{\text {fair }}=(1-\theta)(1-C) / \theta>0
$$

Clearly, this insurance premium is precisely the default risk premium that intermediaries would pay in a hypothetical economy with uninsured deposits and risk-neutral households (in an equilibrium in which intermediaries fail with probability $1-\theta$ ).

Now, suppose that the intermediaries are charged the fair premium $T^{\text {fair }}$. How do they respond? As above, the interesting case occurs when prices exceed pledgeable income, $p>$ $\phi V$. Assuming that intermediaries optimally exhaust their deposit-taking opportunities 
and verifying later, intermediaries' problem boils down to choosing between $B=D / p$ and $B=0$. An intermediary's profit from trading $(B=D / p)$ is

$$
\begin{aligned}
W(D / p) & =\theta\left(D / p \times \phi V / \theta-D\left(1-C+T^{\text {fair }}\right)\right) \\
& =D / p(\phi V-p)+D C+\underbrace{(1-\theta) D(1-C)-\theta D T^{\text {fair }}}_{\text {loss regulator }(=0)} .
\end{aligned}
$$

As above, the first term in the second line is the profit from liquidity provision (which, by $p>\phi V$, is negative); the second term is the "pre-tax" profit from deposit taking; and the last term is the regulator's loss. Since debt guarantees are fairly priced, the regulator's loss is zero. Conversely, an intermediary's profit when it deviates from the anticipated equilibrium path and does not engage in trading $(B=0)$ is

$$
W(0)=\max \left[0, D-D\left(1-C+T^{\mathrm{fair}}\right)\right]=D C-\min \left[D C, D T^{\mathrm{fair}}\right] .
$$

An intermediary that does not engage in trading invests deposits $D$ in the storage technology. For $T^{\text {fair }} \leq C$ (or $\left.C \geq 1-\theta\right)$, the intermediary pays $D(1-C)$ to depositors and $D T^{\text {fair }}$ to the regulator. Intermediary profits are $D C-D T^{\text {fair }} \geq 0$. Conversely, for $T^{\text {fair }}>C$, the intermediary cannot meet its total liability burden with its cash holdings. Depositors are paid $D(1-C)$; the regulator receives the remainder, $D C$; and intermediary profits are zero (alternatively, in this case, the intermediary may not raise deposits in the first place; however, its profit would be zero, too, so $D=1$ is still optimal). Intermediaries strictly prefer to trade if and only if $W(D / p)>W(0)$, or

$$
p<\frac{\phi V}{1-\min \left[C, T^{\text {fair }}\right]} \equiv \hat{p}\left(T^{\text {fair }}\right) \in(\phi V, \phi V / \theta]
$$

The key observation is that negative-NPV trading $(p>\phi V)$ can occur in equilibrium. 
Since intermediary debt is no longer subsidized by the state, it must be the case that the corresponding losses are borne by the intermediaries. Faced with the threat of overpriced guarantees under their outside option of not engaging in trading, intermediaries rationally cross-subsidize market-liquidity provision with their deposit-taking profits.

Proposition 2 Suppose that the regulator levies a premium $T^{\text {fair }}=(1-\theta)(1-C) / \theta$ on the intermediaries. There is an equilibrium with the following properties:

(i) For $D \leq(\phi V)^{2}: d=D, k=\min \left[(\phi V)^{2}-D, K\right]$, and $p=B=I=\min [\phi V, \sqrt{D+K}] \leq$ $\phi V$. Intermediary profits are $W=B(\phi V-p)+D C \geq D C$.

(ii) For $D \in\left((\phi V)^{2}, \hat{p}\left(T^{\text {fair }}\right)^{2}\right]$, where $\hat{p}\left(T^{\text {fair }}\right)=\phi V /\left(1-\min \left[C, T^{\text {fair }}\right]\right): d=D, k=0$, and $p=B=I=\sqrt{D}>\phi V$. Profits are $W=\sqrt{D}(\phi V-\sqrt{D})+D C<D C$.

(iii) For $D>\hat{p}\left(T^{\text {fair }}\right)^{2}$, there is a mixed equilibrium with $d=D, k=0$, and $p=I=$ $\hat{p}\left(T^{\text {fair }}\right)$ in which a fraction $\hat{p}\left(T^{\text {fair }}\right)^{2} / D<1$ of intermediaries buy $B=D / \hat{p}\left(T^{\text {fair }}\right)$ units, and the others do not trade. Profits are $W=\max \left[0, D\left(C-T^{\text {fair }}\right)\right]<D C$.

Proof. Similar to the proof of Proposition 1 and, thus, omitted.

In parts (i) and (ii) of the proposition, guarantees are actuarially fairly priced. Precisely the same equilibrium would prevail in an economy without debt guarantees (but with riskneutral households). In part (iii) of the proposition, some intermediaries do not engage in trading. Thus, the regulator happens to make a positive profit in equilibrium. The more important observation is that, as in the earlier analysis of non-priced guarantees, negative-NPV trading and price bubbles can occur in equilibrium.

It is worth exploring the effects of guarantee pricing in more detail. Given a premium 
$T$, an intermediary's incremental profit from engaging in trading $(B=D / p)$ is

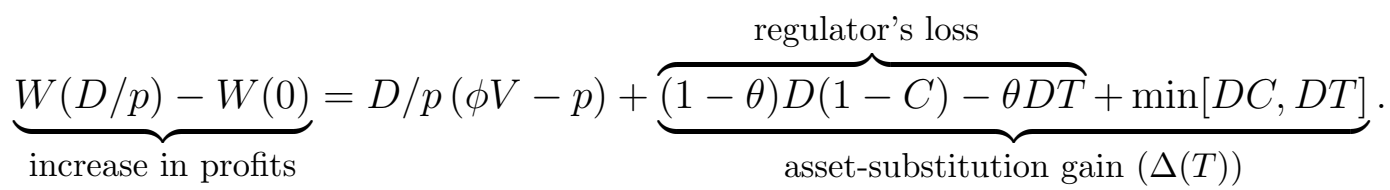

The second term in the asset-substitution gain is the amount by which the $\operatorname{tax} T$ would dilute the pre-tax profit of the intermediary if it did not engage in trading. For an intermediary to be willing to engage in trading, the incremental profit from trading must be non-negative, $W(D / p)-W(0) \geq 0$. The following corollary reports some interesting properties of the asset-substitution gain:

Corollary 1 The asset-substitution gain $\Delta(T)$ has the following properties:

(i) $\arg \max _{T} \Delta(T)=C>0$, and $\Delta(T)>0$ for all $T \in[0, C+(1-\theta) / \theta)$.

(ii) $\Delta\left(T^{\text {fair }}\right)>\Delta(0)$ if and only if $C>(1-\theta) /(2-\theta)$.

(iii) If $C>1-\theta$, then $\Delta(T)>\Delta\left(T^{\text {fair }}\right)$ for some $T>T^{\text {fair }}$.

(iv) $A s C \rightarrow 0$ or $C \rightarrow 1, \Delta\left(T^{\text {fair }}\right)=0$ and, thus, $\hat{p}\left(T^{\text {fair }}\right)=\phi V$.

Proof. Follows from straightforward algebra.

Part (i) of the corollary says that a small rise in the premium from zero makes intermediaries more eager to absorb risk. This is because, for $T<C$, intermediaries' outside-option payoff from not engaging in trading is decreasing faster in $T$ than their payoff from engaging in trading. Part (ii) says that, relative to the case in which guarantees are not priced, fair pricing of guarantees may strengthen intermediaries' incentive to absorb risk. In other words, fair pricing may widen the range of parameter values under which intermediaries engage in negative-NPV liquidity provision. This occurs when deposit taking is sufficiently 


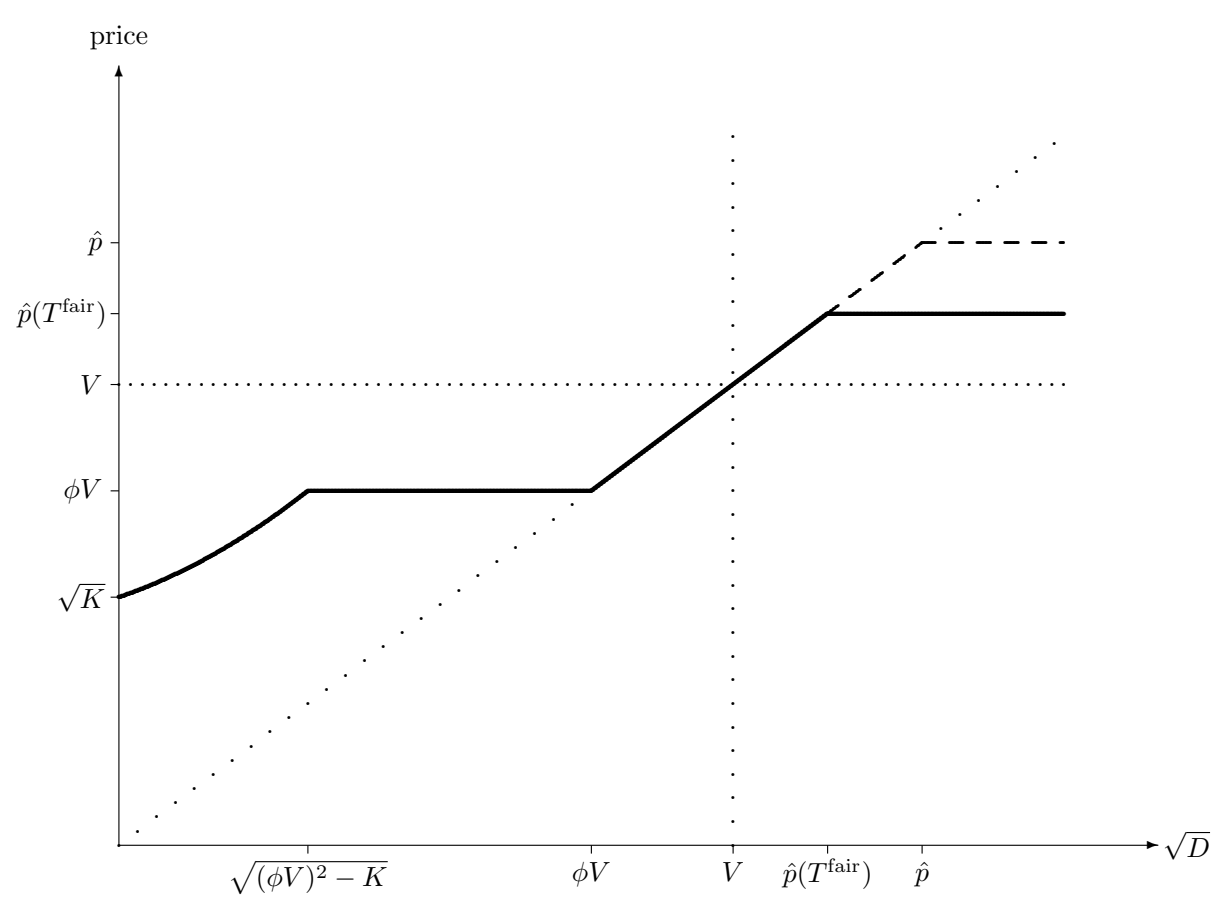

The solid line depicts the equilibrium price $p$ as a function of debt-tied funding liquidity $\sqrt{D}$. The dashed line depicts the benchmark equilibrium with non-priced guarantees.

Figure 2: Fair Pricing (case $C<(1-\theta) /(2-\theta))$

profitable. Part (iii) shows that, in some cases, a regulator who aims to encourage intermediaries to absorb risk should not subsidize such risk taking through underpriced guarantees; instead, he should do precisely the opposite and overprice guarantees (see the next section for a more detailed discussion of this point). Finally, part (iv) says that, in the limit, as the deposit-taking profit margin approaches zero or one, the equilibrium with fair pricing converges to the benchmark equilibrium in an unlevered economy (in which $p \leq \phi V$ ). The intuition is straightforward: When deposit-taking profits are zero, intermediaries have no profits that they can use to cross-subsidize liquidity provision; thus, equilibrium prices cannot possibly exceed pledgeable income. Conversely, when $C=1$, liability burdens are zero; thus, asset-substitution gains and risk-shifting incentives are nil, too.

Figure 2 illustrates Proposition 2 for the case of $C<(1-\theta) /(2-\theta)$. In this case, 
equilibrium prices with fair pricing are, on average, lower than with non-priced guarantees. The more important observation is that negative-NPV trading will sometimes occur in equilibrium. Furthermore, there can be cases in which bubbles $(p>V)$ occur. For instance, suppose that $\theta=0.95, C=0.025, \phi=0.98, V=5$, and $K=10$. In this example, equilibrium prices equal fundamentals, $p=V$, if and only if $D=25$. For $D<25$, prices are below fundamentals, and for $D>25$, they are above fundamentals. Prices are below pledgeable income $\phi V$ if and only if $D<14.01$. Prices are lowest at $D=0$, at which $p=$ $\sqrt{K}=3.162$. They are highest at $D=25.257$ or higher, at which $p=\phi V /(1-C)=5.026$. The spread relative to fundamentals is, then, $\phi /(1-C)-1 \approx 51$ basis points. Whether this magnitude is "high" or "low" is, of course, in the eye of the beholder. It is also worth noting that, following a tiny drop in $\phi$ from 0.98 to $\phi<1-C=0.975$, prices would always be below fundamentals. Policy measures aimed at curbing bubbles might, then, have the unintended consequence of undermining valuable market-liquidity provision.

\subsection{Two Quick Extensions}

This section analyzes two extensions of the base model. The first extension introduces an additional class of investors with exogenous and stochastic asset demand. The question I am interested in is how debt-tied (intermediary) funding liquidity shapes market depthi.e., the sensitivity of prices with respect to changes in investors' asset demand. The second extension analyzes optimal pricing of intermediary debt guarantees. Neither model extension is crucial to the main research question, so the reader may skip this section and move on to the next section, in which I discuss intermediary capital requirements.

Market Depth. Let there be a continuum of institutional investors (e.g., mutual funds) whose mandate is to invest funds on behalf of clients. I sidestep the issue of what constitutes an optimal asset allocation strategy and simply assume that these investors mechanically invest client funds in long-term assets originated by asset originators (thus, 
as in, e.g., Kyle (1985), the investors are "liquidity" or "noise" traders). Net cash inflows, denoted by $F$, are stochastic and drawn from a smooth distribution with support $[0, \bar{F}]$ and mean $\mu_{F}$. This uncertainty is resolved just before the trading stage. For simplicity's sake, I normalize $K$ to zero; thus, intermediaries' funding liquidity is limited to $D$.

Let the intermediaries be dealers that accept buy orders $F / p$ from investors and sell orders $I$ from asset originators. In an equilibrium in which intermediaries strictly prefer $B=D / p$ to $B=0$, market clearing amounts to

$$
D / p=I-F / p
$$

In other words, in equilibrium, intermediaries' risk absorption $D / p$ - the amount by which their inventory increases - must equal net sell order volume $I-F / p$. The market-clearing price, $p(F)=(D+F) / I$, is stochastic from an ex ante perspective. To fix ideas, let us restrict attention to the case in which $p(F)<\hat{p}$ for all $F$ (so that aggregate intermediary demand is $B=D / p)$. Letting $\mu_{p}=\left(D+\mu_{F}\right) / I$ denote the expected price, asset originators' problem is to maximize $I \mu_{p}-\psi(I)$, which yields $I=\mu_{p}$. Thus, $\mu_{p}=\sqrt{D+\mu_{F}}$ and

$$
p(F)=\frac{D+F}{\sqrt{D+\mu_{F}}} .
$$

Thus, while an anticipated rise in debt-tied (intermediary) funding liquidity $D$ leads to worse (higher) average prices for institutional investors (and better prices for asset originators), the actual price is not necessarily increasing in $D$. Formally, $p_{D}(F)<0$ if and only if $D<F-2 \mu_{F}$. Intuitively, an anticipated rise in $D$ has two effects: It raises intermediaries' demand for assets, which leads to higher prices; however, it also causes asset originators to produce more assets, which has the opposite effect on prices. Since the expected price is concave in $D$, the latter effect dominates the former for $D$ small. The sensitivity of the 
price with respect to changes in the order flow $F$ from institutional investors is

$$
p_{F}(F)=\frac{1}{\sqrt{D+\mu_{F}}}
$$

Thus, a rise in $D$ reduces the sensitivity of the price with respect to changes in $F$, so market depth increases. The intuition has, again, to do with the effect of a rise in $D$ on ex ante asset origination: As $D$ rises, asset supply increases; this, in turn, makes actual prices less sensitive with respect to changes in institutional investors' order flow.

Optimal Pricing of Intermediary Debt Guarantees. Recall that, in equilibrium, intermediaries either invest all of their funds in risky assets or do not trade at all. Let the regulator, then, levy a premium $T^{r}$ on risky intermediaries $(B>0)$ and a premium $T^{s}$ on safe ones $(B=0)$. Society is assumed to have the following wish list:

(i) The regulator must not make losses in expectation and not engage in cross-subsidization across intermediaries: $T^{r} \geq(1-\theta)(1-C) / \theta$.

(ii) Safe intermediaries do not pay higher premia than risky ones: $T^{r} \geq T^{s}$.

(iii) Safe intermediaries' premium respects limited liability: $T^{s} \leq C$.

Condition (i) follows from society's aversion to government-sponsored subsidization or cross-subsidization of intermediaries. Condition (ii) is a simple fairness condition (it would also be an incentive-compatibility condition if intermediaries could disguise safe activities as risky ones). Condition (iii) follows from limited liability. As above, the interesting case occurs when prices exceed pledgeable income, $p>\phi V$. An intermediary prefers $B=D / p$ to $B=0$ if

$$
D / p\left(\phi V / \theta-D\left(1-C+T^{r}\right)\right) \geq D-D\left(1-C+T^{s}\right)
$$


which reduces to

$$
p \leq \frac{\phi V}{1-\left(T^{s}-\left(\theta T^{r}-(1-\theta)(1-C)\right)\right)} \equiv \hat{p}\left(T^{r}, T^{s}\right)
$$

Suppose, for a moment, that the regulator's objective is to maximize liquidity provision (i.e., $\phi$ is "small"). The regulator's problem is to

$$
\max _{\left(T^{r}, T^{s}\right)} \hat{p}\left(T^{r}, T^{s}\right)
$$

subject to (i) to (iii). This problem is solved for $T^{s}=C$ and

$$
T^{r}=\max [C,(1-\theta)(1-C) / \theta] .
$$

Thus, for $C \geq 1-\theta$, the optimal pricing scheme involves flat pricing, $T^{r}=T^{s}=C$. This policy taxes away inactive intermediaries' deposit-taking profits-i.e., it penalizes inactivity as much as possible. The regulator may, then, want to reward liquidity provision by levying a lower premium on risky intermediaries; however, he is constrained by his mandate to not charge a higher premium to safe intermediaries than to risky ones. For $C<1-\theta$, the optimal policy involves fair pricing for risky intermediaries. In this case, the regulator is constrained by his mandate to not cross-subsidize across intermediaries.

For this policy to not lead to an unhealthy bubble $(p>V)$, it must be the case that $\hat{p}\left(T^{r}, T^{s}\right) \leq V$. Substituting for $\left(T^{r}, T^{s}\right)$, one can show that this constraint is not binding if and only if $\phi \leq \max [\theta, 1-C]$. If this condition is not satisfied, an optimal pricing scheme solves $\hat{p}\left(T^{r}, T^{s}\right)=V$, subject to (i) to (iii). As $\phi$ approaches one, an optimal policy is $T^{r}=T^{\text {fair }}$ and $T^{s}=0$, and the equilibrium converges to $p=\min [\phi V, \sqrt{D+K}]$. The question that arises is whether such fine-tuning of guarantee premia is feasible in practice. It may not be, so it is worth considering an alternative - namely, capital requirements. 


\section{Capital Requirements}

Above, I have shown that, unless guarantees are properly priced, intermediaries may engage in too much risk taking, leading to unhealthy price bubbles. The traditional response would be to impose equity capital requirements on intermediaries. The aim of this section is to explore the effectiveness of capital requirements within the context of my model.

Suppose that intermediaries are required to have equity capital $\tau \in(0,1)$ per dollar of risk-weighted assets. Risky assets have a risk weight of one, and safe assets (storage) have a risk weight of zero. For simplicity's sake, I restrict attention to the case in which guarantees are not priced, $T=0$. As in the earlier analysis, it is optimal for intermediaries to exhaust their deposit-taking opportunities. Thus, an intermediary's problem is to

$$
\begin{aligned}
\max _{(k \leq K, B \geq 0)} & W=B(\phi V-p)+D C+(1-\theta) \max [D(1-C)-(D+k-B p), 0] \\
\text { s.t. } & \\
& B \leq \frac{D+k}{p} \\
& k \geq \tau B p
\end{aligned}
$$

where (4) is the resource constraint, and (5) is the regulatory capital constraint.

First, consider the case in which trading has positive NPV, $p<\phi V$. If the regulatory capital constraint (5) is not binding, then $k=K$ and $B=(D+K) / p$. Thus, (5) is slack if and only if $\tau \leq K /(D+K)$. I momentarily restrict attention to this case; the case of $\tau>K /(D+K)$ will be considered later. Thus, in an equilibrium in which $p<\phi V$, regulatory capital constraints are not binding. Intermediaries raise deposits $D$ and capital $K$ and invest all funds in risky assets. Consider, then, the more interesting case in which prices exceed pledgeable income, $p>\phi V$. In this case, intermediaries will seek to minimize their owners' investment contribution, so the regulatory capital constraint (5) must be 
binding. Substituting for $k=\tau B p$, intermediaries' problem reduces to

$$
\begin{array}{rl}
\max _{B \geq 0} & W=B(\phi V-p)+D C+(1-\theta) \max [(1-\tau) B p-D C, 0], \\
\text { s.t. } & \\
B & \leq \frac{D}{(1-\tau) p}, \\
B & \leq \frac{K}{\tau p}
\end{array}
$$

where (6) follows from $B p \leq D+k=D+\tau B p$, and (7) follows from $k=\tau B p \leq K$. By $\tau \leq K /(D+K)$, (7) is implied by (6), so (7) is slack. As in the earlier analysis, intermediaries either invest all funds in risky assets, $B=D /((1-\tau) p)$, or do not trade at all, $B=0$. Intermediaries prefer to trade if

$$
p \leq \frac{\phi V}{1-(1-\tau)(1-\theta)(1-C)} \equiv \hat{p}(\tau) \in(\phi V, \phi V / \theta)
$$

A rise in capital requirements $\tau$ tightens this inequality. This effect tends to make intermediaries less willing to engage in trading. However, a rise in capital requirements also leads to higher trading volumes $(B=D /((1-\tau) p))$ in an equilibrium in which intermediaries do engage in trading. Thus, the overall effect of capital requirements is ambiguous:

Proposition 3 Let $T=0$, and suppose that intermediaries are required to have equity capital $\tau \leq K /(D+K)$ per dollar of risk-weighted assets.

(i) For $D \leq(1-\tau)(\phi V)^{2}$, the equilibrium is as in Proposition 1. Within this range, capital requirements have no effect on market outcomes.

(ii) For $D \in\left((1-\tau)\left(\phi V^{2}\right),(1-\tau) \hat{p}(\tau)^{2}\right]$, where $\hat{p}(\tau)$ is given by (8), the equilibrium is

$$
p=B=I=\sqrt{\frac{D}{1-\tau}}>\phi V .
$$




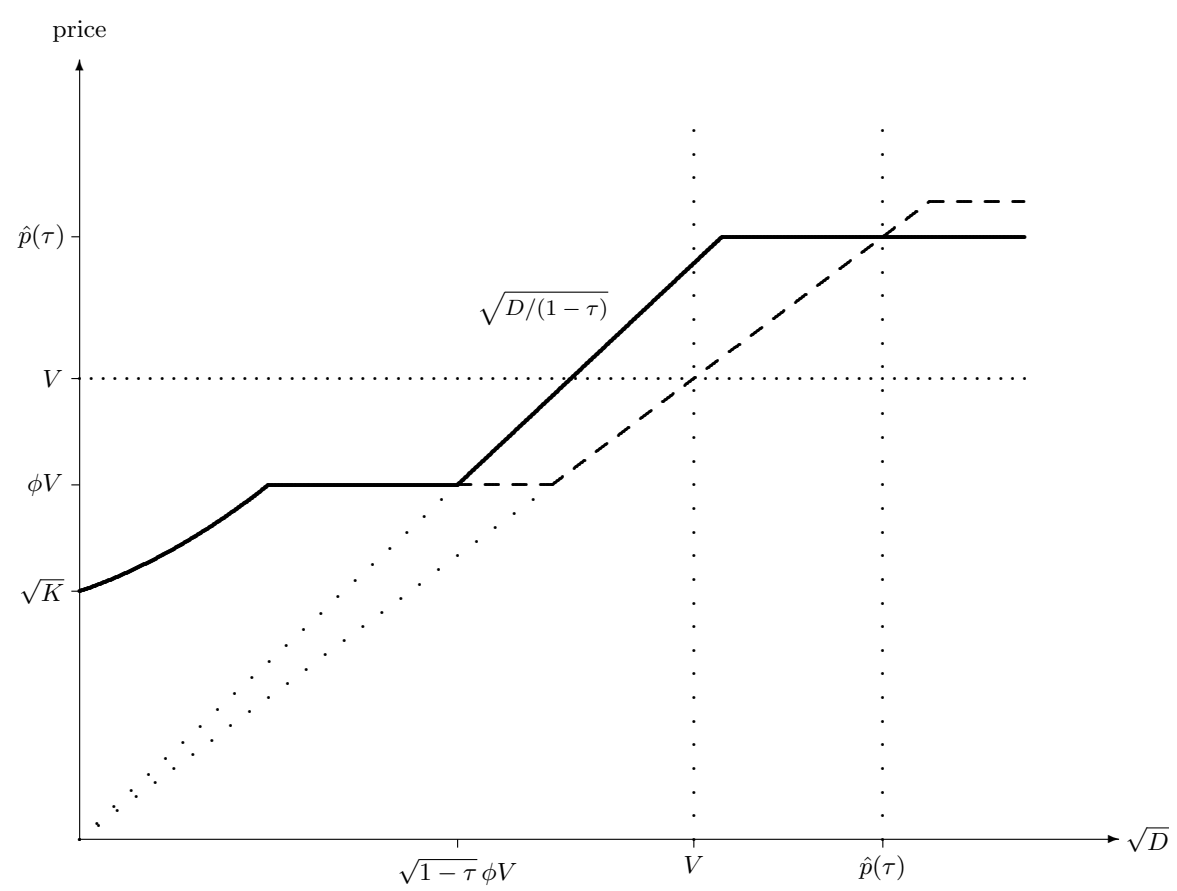

The solid line depicts $p$ as a function of debt-tied funding liquidity $\sqrt{D}$. The dashed line depicts the equilibrium in the absence of capital requirements. For $\sqrt{D}>\sqrt{1-\tau} V$, equilibrium prices exceed fundamentals. Thus, capital requirements can spur bubbles.

Figure 3: Capital Requirements $(\tau<K /(D+K))$

Thus, a rise in capital requirements leads to higher asset prices: $\tau \uparrow \Rightarrow p \uparrow$

(iii) For $D>(1-\tau) \hat{p}(\tau)^{2}$, there is a mixed trading equilibrium with $p=I=\hat{p}(\tau)>\phi V$. Within this range, a rise in capital requirements leads to lower prices: $\tau \uparrow \Rightarrow p \downarrow$.

Proof. The proof follows from the discussion in the text and market clearing.

Figure 3 illustrates the proposition. A first observation is that prices may be higher with capital requirements than without. The reason is that intermediaries, when engaging in trading, invest in risky assets not only their deposits, but also the equity capital that they must raise to meet their capital requirements. This holds true even if trading has negative NPV: The alternative - investing equity capital in safe storage - is even less attractive for shareholders due the windfall gains that it would create for liability hold- 
ers. Thus, as capital requirements rise, more money is chasing assets, leading to higher prices. In other words, capital requirements can spur price bubbles. However, there also is range of parameter values for which capital requirements lead to lower prices. Even though capital requirements lead to higher trading volumes in an equilibrium in which all intermediaries engage in trading, they also make intermediaries less willing to engage in negative-NPV trading - after all, negative-NPV trading is costly. This effect dominates the price-inflating effect when debt-tied funding liquidity is relatively high, $D>\hat{p}(\tau)^{2}$. As capital requirements $\tau$ rise, $\sqrt{D /(1-\tau)}$ becomes steeper, and $\hat{p}(\tau)$ shifts downward. In the limit, as $\tau \rightarrow K /(D+K)$, the asset market equilibrium converges to

$$
p=\min \left[\frac{\phi V}{1-\frac{D}{D+K}(1-\theta)(1-C)}, \sqrt{D+K}\right] .
$$

"Substantial" Capital Requirements. Next, consider the case in which $\tau>$ $K /(D+K)$. In this case, regulatory capital constraints are always binding. If $p<$ $\phi V$ in equilibrium, then, by (5), $B=K /(\tau p)$. Intermediaries hold safe-assets buffers $D+K-B p=D-(1-\tau) K / \tau>0$. Indeed, intermediaries' "equity-tied" funding-liquidity constraint is binding: By $K<\tau D /(1-\tau)$, intermediaries are unable to raise the regulatory equity capital that they would have to raise if they invested all funds in risky assets. Conversely, if $p>\phi V$, then either $B=0$ or $B=K /(\tau p)$. In the former case, intermediaries hold safe-assets buffers $D$, and in the latter, they hold safe-assets buffers $D-(1-\tau) K / \tau$. Intermediaries prefer to trade $(B>0)$ if and only if (i) trading offers asset-substitution gains, $\tau<K /(D C+K)$, and (ii) trading losses are not too high,

$$
p \leq \frac{\phi V}{1-(1-\theta)\left(1-\tau \frac{D C+K}{K}\right)} .
$$


Summing up, for $\tau \in(K /(D+K), K /(D C+K))$, the equilibrium price is

$$
p=\min \left[\frac{\phi V}{1-(1-\theta)\left(1-\tau \frac{D C+K}{K}\right)}, \sqrt{K / \tau}\right]
$$

-i.e., a rise in capital requirements has an unambiguously negative effect on the equilibrium price. However, since the first term in the minimum operator exceeds pledgeable income, unhealthy price bubbles will still occur for some parameter constellations.

Finally, for $\tau \geq K /(D C+K)$, risky trading no longer generates asset-substitution gains. In fact, intermediaries never fail. To see this, note that, conditional on trading $(B=K /(\tau p))$, intermediaries hold safe-assets buffers

$$
D+K-B p=D-(1-\tau) K / \tau \geq D(1-C),
$$

by $\tau \geq K /(D C+K)$. Since trading no longer yields asset-substitution gains, prices cannot possibly exceed pledgeable income, and the equilibrium reduces to $p=\min [\phi V, \sqrt{K / \tau}]$. Thus, prices will be severely depressed. The upside is that there are no bubbles. Indeed, if the objective of the regulator is to curb bubbles for any possible "realization" of $\phi$, then the optimal capital requirement is $\tau=K /(D C+K)$. Under this policy, intermediary debt is safe, so intermediaries have no incentive to engage in risk shifting. In the limit, as $\tau \rightarrow 1$, the equilibrium converges to the equilibrium in a non-intermediated economy, $p=\min [\phi V, \sqrt{K}]$. Furthermore, as $C \rightarrow 0$ (i.e., deposit-taking rents approach zero), the equilibrium under a bubble-curbing policy $(\tau=1)$ converges to $p=\min [\phi V, \sqrt{K}]$.

In sum, the analysis illustrates some of the trade-offs that regulators may encounter when setting intermediary capital requirements. To curb bubbles, capital requirements must be "drastic." However, drastic capital requirements will also undermine liquidity provision in circumstances in which bubbles would not occur in the first place. Relatively low capital requirements, in turn, mitigate or eliminate bubbles in some cases; however, this 
may come at the expense of aggravating or creating bubbles in other cases. The upside is that, ironically, capital requirements may help to encourage risk taking in situations that are characterized by excessive risk avoidance and under-provision of liquidity. The economic intuition behind this seemingly paradoxical observation is very simple: Capital requirements shift capital from the non-banking sector into the levered banking sector, where - in view of the alternatives - it may be used to fund additional risk taking.

\section{Short Sales}

To what extent are bubble equilibria robust to the removal of short-sale constraints? This section provides a brief discussion. In much of the literature on the limits of arbitrage, profit opportunities from mispricing arise from exogenous shocks to prices. Investors will, then, seek to take advantage of such opportunities; however, frictions (e.g., funding constraints) may prevent them from doing so. In contrast, in my model, "arbitrage" opportunities arise endogenously from intermediaries' eagerness to invest in risky assets. Crucially, the intermediaries, acting in the interest of their owners, may not necessarily want to take advantage of such opportunities. This is because long negative-NPV positions could offer higher "private" (i.e., risk-shifting) benefits than short positive-NPV positions.

To see this, consider a candidate equilibrium in which prices exceed pledgeable income, $p>\phi V$, and suppose that an intermediary engages in (naked) short-selling and sells $Z$ shares (asset units), generating income $Z p$ at date 1. Suppose, too, that other investorsviz., intermediary owners - cannot engage in short selling (e.g., because of short-sale constraints for non-institutional investors). The case in which intermediary owners can engage in short selling will be considered below. Thus, at date 2, the intermediary faces a statecontingent liability to the party to whom it sold the shares. This liability amounts to $Z \times \phi V / \theta$ in the high state of the economy and to zero in the low state. Following much of 
the literature on the limits of arbitrage, I posit that the liability must be collateralized by putting cash in a margin account. Restricting attention to $T=0$, and normalizing capital requirements to zero, an intermediary's collateral constraint is

$$
Z \times \phi V / \theta \leq D+K+Z p
$$

where the right-hand side is the intermediary's cash position at date 1 , given that it raised deposits $D$, issued equity $K$, and sold $Z$ shares. This expression reduces to

$$
Z \leq \frac{D+K}{\phi V / \theta-p}
$$

Thus, an intermediary's profit from going short is

$$
\underbrace{\frac{D+K}{\phi V / \theta-p} \times(p-\phi V)}_{\text {NPV short }>0}+D C+\theta D(1-C) .
$$

The last term is the asset-substitution gain from going short and failing in the high state of the economy. The intermediary's profit from taking a long position $(B=D / p)$ is

$$
\underbrace{D / p \times(\phi V-p)}_{\text {NPV long }<0}+D C+(1-\theta) D(1-C) .
$$

Intermediaries have no incentive to go short if the profit from taking a long position is not lower than the profit from going short. This amounts to

$$
\underbrace{\left(\frac{D+K}{\phi V / \theta-p}+D / p\right)(p-\phi V)}_{\Delta \text { trading profits }>0} \leq \underbrace{(1-2 \theta) D(1-C)}_{\Delta \text { asset-subst. gains }} .
$$

The left-hand side is the difference between the trading profits from short and long po- 
sitions, and the right-hand side is the difference between the asset-substitution gains. A necessary condition for intermediaries to have no incentive to go short is that taking a long position offers higher asset-substitution gains than taking a short position, $\theta<1 / 2$. Thus, in risky economies, some bubble equilibria are robust to the possibility of intermediary short sales. Straightforward algebra shows that condition (9) is not satisfied at $p=\hat{p}$, so the bubbliest bubble equilibrium does not survive. However, others do.

Even though intermediaries' owners may not want their intermediaries to engage in short sales, they still may want to engage in personal short sales, if they can (i.e., do not face short-sale constraints). Consider a candidate equilibrium in which prices exceed pledgeable income, and, to fix ideas, suppose that intermediaries find it suboptimal to engage in short sales and are not permitted to extend personal loans to their bankers (owners). ${ }^{8}$ A banker's personal short-sale collateral constraint is $Z \leq K /(\phi V / \theta-p)$. Restricting attention to equilibria with $p \in(\phi V, \hat{p})$, market clearing amounts to

$$
D / p=p+\frac{K}{\phi V / \theta-p}
$$

Thus, personal short sales will cause prices to drop. This is desirable if there is a bubble in the absence of short sales, but it is undesirable if prices are below fundamentals. Thus, short-sale constraints may or may not be desirable - as always, regulation involves tradeoffs. The analysis also suggests yet another reason why capital requirements can have the unintended consequence of creating unhealthy price bubbles. As intermediaries face higher capital requirements, investors may have to commit more equity capital to the intermediaries. This implies that less capital is available for the purpose of collateralizing personal short-sale positions that would help to mitigate price bubbles.

\footnotetext{
${ }^{8}$ If intermediaries could extend personal loans to bankers, a trade-off would arise: The risk-shifting benefits from investing deposits in negative-NPV long trades would have to be traded off against the (i) risk-shifting benefits from extending risky loans to bankers; (ii) bankers' trading profits from taking positive-NPV short positions; and (iii) the reduction in intermediary trading losses.
} 


\section{$6 \quad$ Ring Fencing}

Would society be better off if banks' trading activities were ring-fenced? The essence of the ring-fencing policy proposals (Vickers et al., 2011; Liikanen et al., 2011) is straightforward: Banks' core deposits must not be put at risk by their trading (or other investment banking) activities. Ultimately, this boils down to putting deposits into bankruptcy-remote subsidiaries whose prospects are not affected by the prospects of banks' trading businesses (including banks' financial stakes in other investors' trading businesses).

To evaluate the merits of ring fencing in the context of my model, I run two experiments. The first experiment compares the non-intermediated benchmark economy in Section 2.2 with the intermediated economy in Section 3.1. One may argue that such a comparison is not entirely appropriate since, in this model, funding liquidity just happens to be much lower in the non-intermediated economy. Thus, in a second step, I also compare an intermediated but unlevered economy with the levered economy in Section 3.1.

Experiment 1. As seen in Section 2.2, equilibrium prices and, thus, asset-origination levels in a non-intermediated economy are $p=I=\min [\phi V, \sqrt{K}]$. Under the unconstrained efficient allocation, prices would equal fundamentals, $p=V$. Thus, the welfare gap is

$$
L^{\text {ring }}=V-\min [\phi V, \sqrt{K}]=\max [(1-\phi) V, V-\sqrt{K}]>0 .
$$

Clearly, for the non-intermediated ("ring-fenced") economy to potentially outperform the intermediated economy, there must be a bubble in the intermediated economy. As seen earlier, this occurs if and only if $1-\phi<(1-\theta)(1-C)$ and $\sqrt{D}>V$. The welfare gap in the intermediated economy is, then,

$$
L^{\text {int }}=\min \left[V\left(\frac{\phi}{1-(1-\theta)(1-C)}-1\right), \sqrt{D}-V\right]>0 .
$$


I now compare the ring-fenced (i.e., non-intermediated) economy with the intermediated economy. First, consider the case in which $\sqrt{K} \geq \phi V$, so that $L^{\text {ring }}=(1-\phi) V$. Clearly, if, at the bubbliest equilibrium, the intermediated economy outperforms the ring-fenced one, then the intermediated economy dominates. The bubbliest equilibrium occurs at $V=(1-(1-\theta)(1-C)) \sqrt{D} / \phi \equiv V^{\text {bubblemax }}$ (cf., Fig. 1), at which the welfare gap in the intermediated economy is

$$
L^{\mathrm{int}}=\sqrt{D}\left(1-\frac{1-(1-\theta)(1-C)}{\phi}\right)>0
$$

Also, at $V=V^{\text {bubblemax }}$, the welfare gap in the ring-fenced economy is

$$
L^{\text {ring }}=\frac{1-\phi}{\phi}(1-(1-\theta)(1-C)) \sqrt{D}>0 .
$$

Straightforward algebra shows that, at $V=V^{\text {bubblemax }}, L^{\text {ring }} \geq L^{\text {int }}$ if and only if

$$
\phi \leq \frac{2(1-(1-\theta)(1-C))}{2-(1-\theta)(1-C)} \equiv \bar{\phi} \in(1-(1-\theta)(1-C), 1)
$$

In other words, if the wedge between social and private returns is sufficiently large, $1-\phi \geq$ $1-\bar{\phi}>0$, then the intermediated economy dominates the ring-fenced one. The welfare loss from under-provision of liquidity in a ring-fenced economy always outweighs the welfare loss from a potential bubble in an intermediated economy. Conversely, for $\phi>\bar{\phi}$, there are cases - namely, sufficiently severe bubbles - in which society is better off with ring fencing. The bottom-line is that ring fencing is often, albeit not always, undesirable. The obvious caveat is that the analysis proposed here abstracts from other costs of heightened intermediary risk-taking, such as contagion costs, disruption of payment systems, etc. Thus, another way to see the analysis is that it illustrates that ring fencing can, in some cases, be desirable even if one abstracts from such hard-to-assess systemic costs. 
Next, consider the case in which $\sqrt{K}<\phi V$, so that $L^{\text {ring }}=V-\sqrt{K}$. At $V=V^{\text {bubblemax }}$, we have $L^{\text {ring }} \geq L^{\text {int }}$ if and only if

$$
\phi \leq \frac{2 \sqrt{D}}{\sqrt{D}+\sqrt{K}}(1-(1-\theta)(1-C))
$$

A rise in $D$ (more funding liquidity in the intermediated economy) relaxes this inequality, and a rise in $K$ (more liquidity provision in the ring-fenced economy) tightens it. The right-hand side of the inequality may exceed one, so even at $\phi=1$, the intermediated economy may dominate the ring-fenced economy. This is because when $K$ is very low, liquidity provision in the ring-fenced economy will be severely suppressed, the cost of which outweighs the welfare loss from bubbles in the intermediated economy.

Experiment 2. In a second step, I compare the intermediated economy in Section 3.1 with a hypothetical economy in which $D$ is available not in the form of "cheap" deposits, but in the form of competitively priced (and uninsured) funds - say, equity. Thus, in the ring-fenced economy,

$$
L^{\text {ring }}=\max [(1-\phi) V, V-\sqrt{D+K}]
$$

Not surprisingly, the welfare loss in the ring-fenced economy is weakly lower than before due to the additional funding liquidity that is now available in the ring-fenced economy. For $\sqrt{D+K} \geq \phi V$, the comparison is similar to the one above. For $\sqrt{D+K}<\phi V$, $p=\sqrt{D+K}$ in both economies (cf., Fig. 1), so neither economy dominates the other.

\section{Conclusion}

I studied a simple model of market-liquidity provision by levered intermediaries that, besides operating trading desks, run deposit-taking franchises, providing them with cost-offunding advantage. Leverage can, in some cases, cause intermediaries to cross-subsidize 
liquidity provision with their proprietary rents from deposit taking. This helps to counteract liquidity-provision frictions, stimulating asset origination ex ante. However, liquidity provision may also overshoot, leading to price bubbles and causing asset origination to become excessive. Capital requirements are no panacea: They can spur intermediary risktaking, create bubbles, or exacerbate existing bubbles. I also show that balance-sheet segregation - ring fencing of trading activities - may be undesirable. Overall, the analysis suggests that regulations restricting deposit-taking banks' engagement in trading may have a lasting impact on market-liquidity provision. Non-bank liquidity providers may not (completely) fill the void left by banks. The welfare implications are ambiguous.

\section{References}

Acharya, V., Cooley, T., Richardson, M., and I. Walter, 2010, Manufacturing tail risk: A perspective on the financial crisis of 2007-2009. Foundations and Trends in Finance 4, Issue 4, 247-325.

Acharya, V., and H. Naqvi, 2012, The seeds of a crisis: A theory of bank liquidity and risk taking over the business cycle, Journal of Financial Economics 106, 349-366.

Allen, F., and D. Gale, 1994, Limited market participation and volatility of asset prices, American Economic Review 84, 933-955.

Allen, F., and D. Gale, 2000, Bubbles and crises, Economic Journal 110, 236-255.

Arping, S., 2013, Proprietary trading and the real economy, University of Amsterdam.

Barlevy, G., 2014, A leverage-based model of speculative bubbles, Journal of Economic Theory 153, 459-505.

Blum, J., 1999, Do capital adequacy requirements reduce risk in banking?, Journal of Banking and Finance 23, 755-771.

Brunnermeier, M., and L. Pedersen, 2009, Market liquidity and funding liquidity, Review of Financial Studies 22, 2201-2238.

Calem, P., and R. Rob, 1999, The impact of capital-based regulation on bank risk-taking, Journal of Financial Intermediation 8, 317-352.

Chacko, G., Jurek, J., and E. Stafford, 2008, The price of immediacy, Journal of Finance 63, 1253-1290.

DeAngelo, H., and R. Stulz, 2014, Liquid-claim production, risk management, and bank capital structure: Why high leverage is optimal for banks, Journal of Financial Economics, forthcoming. 
Demsetz, H., 1968, The cost of transacting, Quarterly Journal of Economics 82, 3353.

Diamond, D., and P. Dybvig, 1983, Bank runs, deposit insurance, and liquidity, Journal of Political Economy 91, 401-419.

Duffie, D., Gârleanu, N., and L. Pedersen, 2005, Over-the-counter markets, Econometrica 73, $1815-1847$.

Duffie, D., Gârleanu, N., and L. Pedersen, 2007, Valuation in over-the-counter markets, Review of Financial Studies 20, 1865-1900.

Duffie, D., 2012a, Market making under the proposed Volcker Rule, Stanford University.

Duffie, D., 2012b, Drawing boundaries around and through the banking system, In: World Economic Forum (Ed.), The Financial Development Report 2012, 39-46.

Eisfeldt., A., 2004, Endogenous liquidity in asset marktes, Journal of Finance 59, 1-30.

Farhi, E., and J. Tirole, 2012, Bubbly liquidity, Review of Economic Studies 79, 678-706.

Foucault, T., Pagano, M., and A. Roell, 2013, Market Liquidity, Oxford University Press, Oxford.

Glosten, L., and P. Milgrom, 1985, Bid, ask, and transaction prices in a specialist market with heterogeneously informed traders, Journal of Financial Economics 14, 71-100.

Gromb, D., and D. Vayanos, 2002, Equilibrium and welfare in markets with financially constrained arbitrageurs, Journal of Financial Economics 66, 361-407.

Gromb, D., and D. Vayanos, 2010a, Limits of arbitrage, Annual Review of Financial Economics, $2,251-275$.

Gromb, D., and D. Vayanos, 2010b, A model of financial market liquidity based on intermediary capital, Journal of the European Economic Association 8, 456-466.

Grossman, S., and M. Miller, 1988, Liquidity and market structure, Journal of Finance 38, 617633.

He, Z., and A. Krishnamurthy, 2013, Intermediary asset pricing, American Economic Review 103, 732-770.

Hellmann, T., Murdock, K., and J. Stiglitz, 2000, Liberalization, moral hazard in banking, and prudential regulation: Are capital requirements enough?, American Economic Review 90, 147-165.

Holmström, B., and J. Tirole, 1998, Private and public supply of liquidity, Journal of Political Economy 106, 1-40.

International Monetary Fund, 2014, Global Financial Stability Report, April 2014, Washington.

Jensen, M., and W. Meckling, 1976, Theory of the firm: managerial behavior, agency costs, and ownership structure, Journal of Financial Economics 3, 205-360. 
Juang, J., and J. Wang, 2010, Market liquidity, asset prices, and welfare, Journal of Financial Economics 95, 107-127.

Kashyap, A., Rajan, R., and J. Stein, 2002, Banks as liquidity providers: An explanation for the coexistence of lending and deposit-taking, Journal of Finance 57, 33-73.

Koehn, M., and A. Santomero, 1980, Regulation of bank capital and portfolio risk, Journal of Finance 35, 1235-1244.

Krishnamurthy, A., and A. Vissing-Jorgensen, 2012, The aggregate demand for treasury debt, Journal of Political Economy 120, 233-267.

Kyle, A., 1985, Continuous auctions and insider trading, Econometrica 53, 1315-1336.

Liikanen, E., et al., 2012, Final report, High-Level Expert Group on Reforming the Structure of the EU Banking Sector.

Malherbe, F., 2014, Self-fulfilling liquidity dry-ups, Journal of Finance 69, 947-970.

Moreira, A., and A. Savov, 2013, The macroeconomics of shadow banking, Yale University.

Nagel, S., 2014, The liquidity premium of near-money assets, University of Michigan.

Noss, J., and R. Sowerbutts, 2012, The implicit subsidy of banks, Bank of England.

Shleifer, A., and R. Vishny, 1997, The limits of arbitrage, Journal of Finance 52, 35-55.

Stein, J., 2012, Monetary policy as a financial stability accelerator, Quarterly Journal of Economics $127,57-95$.

Stiglitz, J., and A. Weiss, 1981, Credit rationing in markets with imperfect information, American Economic Review 71, 393-410.

Stoll, H., 1978, The supply of dealer services in securities markets, Journal of Finance 33, 1133-51.

Thakor, A., 2012, The economic consequences of the Volcker Rule, Center for Capital Markets Competitiveness.

Thakor, A., 2014, Bank capital and financial stability: An economic trade-off or a Faustian bargain?, Annual Review of Financial Economics 6, 185-223.

Tirole, J., 2006, The Theory of Corporate Finance, MIT Press, Cambridge.

Tirole, J., 2011, Illiquidity and all its friends, Journal of Economic Literature 49, 287-325.

Vayanos, D., and J. Wang, 2012, Theories of liquidity, Foundations and Trends in Finance 6, Issue $4,221-317$.

Vickers, J., et al., 2011, Final report, Independent Commission on Banking. 